\title{
Potential of Integrating Biochar and Deficit Irrigation Strategies for Sustaining Vegetable Production in Water-limited Regions: A Review
}

\author{
Manpreet Singh, Rupinder Kaur Saini, and Sukhbir Singh \\ Department of Plant and Soil Science, Texas Tech University, Lubbock, \\ TX 79409
}

\section{Sat Pal Sharma \\ Department of Vegetable Science, Punjab Agricultural University, Ludhiana, Punjab 141004, India}

Additional index words. drought stress, physiology, semi-arid, water use efficiency, water holding capacity, yield losses

\begin{abstract}
Water shortage is one of the major challenges faced by the current agricultural systems worldwide, especially in arid and semi-arid regions. Deficit irrigation (DI), a water-saving strategy of applying less water than crop evapotranspiration $\left(\mathbf{E} T_{c}\right)$ demands, has been extensively investigated in different crops, including waterintensive vegetables. The DI strategies such as regulated deficit irrigation (RDI) and partial root zone drying (PRD) generally increase water use efficiency (WUE) and have emerged as potential practices to save water for agricultural sustainability. However, in view of the sensitivity of shallow-rooted vegetable crops to water stress, DI is often associated with yield losses. A review of 134 DI reports of vegetable crops revealed significant reductions in yield under all DI levels in $52 \%$ of cases and yields statistically similar to those of full irrigation $\left(100 \% \mathrm{ET}_{\mathrm{c}}\right.$ in most cases) under small water deficits in $44 \%$ of cases, thereby raising concerns about the sustainability of vegetable production under DI. Biochar, a carbon-rich co-product of pyrolysis of organic matter, is increasingly undergoing study as a soil amendment to mitigate drought stress and is being explored as an additional practice with DI to minimize the yield losses due to water deficits. This work reviews the effects of biochar application on growth, yield, physiology, and WUE of different vegetable crops under DI regimes to determine the potential of biochar and DI used in combination to sustain vegetable productivity in water-limited areas. Overall, the addition of biochar under DI has helped to compensate for yield losses of vegetables and further enhanced WUE. However, field studies investigating long-term soil-biochar interactions that strongly conclude the impact of biochar under moisture stress conditions are lacking.
\end{abstract}

At present, global agriculture, especially vegetable production, is being challenged to meet the food and nutritional demands of the ever-increasing population. The growing food demand is placing pressure on natural resources such as land and water. Irrigated agriculture is undoubtedly the largest consumer of freshwater, accounting for approximately more than two-thirds of the total fresh water use (Chai et al., 2015). Agriculture is considered one of the most inefficient water users and causes exploitation of water resources in many areas worldwide (FAO, 1993). As a consequence, water scarcity has become a critical factor for crop production, especially in arid and semi-arid areas. For instance, the Ogallala aquifer, a major source of irrigation water in the Southern High Plains of the United States, experienced a

Received for publication 5 June 2019. Accepted for publication 30 July 2019.

S.S. is the corresponding author. E-mail: s.singh@ ttu.edu. decrease of $\approx 4.8 \mathrm{~m}$ in the water level since the beginning of dominant extraction (1950s) and an overall decline of $\approx 0.2 \mathrm{~m}$ during 2013-15 (McGuire, 2017). Every year, approximately two-thirds of the world's population experience a severe water shortage for at least 1 month (Mekonnen and Hoekstra, 2016). Considering the conflict regarding water allocation for agriculture and other sectors, more restrictions on irrigation water with the current production systems are inevitable in the near future. Water shortages have frequently exposed crops to drought stress, which is often accompanied by heat and salinity stress. In contemporary agriculture, drought stress is, in fact, the key limiting factor responsible for growth and yield reductions of crop plants (Bodner et al., 2015). Recently, as a result, efficient use of irrigation water and increments in WUE of crop plants are major concerns of researchers and agronomists. Water conservation practices such as drip irrigation, protected cultivation, and mulching have significantly contributed to the improvement in WUE by reducing evapotranspiration (ET) and runoff losses (Costa et al., 2007; Kirnak and Demirtas, 2006). However, there is still an opportunity to devise more cultural and irrigation strategies to make production systems more waterefficient and sustainable. The crop yields are generally highest with optimal water application, but crops can adapt and produce reasonably well under limited water supply conditions (FAO, 2002). Deficit irrigation (DI) is a strategy of applying less water than ET demands with the objective of improving WUE by eliminating the irrigation with a nonsignificant impact on yield (Kirda, 2002). The DI technique used for a number of crops, including vegetables in water-limited areas, exposes the plants to different levels of moisture stress. Many agronomic crops like cotton (Gossypium hirsutum L.), safflower (Carthamus tinctorius L.), and several fruit crops like grapevine (Vitis vinifera L.) and citrus, which are well-adapted to water stress, have been reported to produce yields statistically similar to those of full irrigation under DI regimes (Costa et al., 2007; Singh et al., 2016; Yang et al., 2015). For most vegetable crops, water deficit is often accompanied by yield losses and deterioration of quality due to high water sensitivity (Costa et al., 2007); however, fewer studies showing nonsignificant yield reductions in vegetable crops in response to DI have also been reported in literature (Ahmadi et al., 2014; Du et al., 2017; Nagaz et al., 2012). The water sensitivity of fast-growing vegetable crops is attributed to two main reasons. First, most vegetable crops have shallow root systems with effective root zone lying within the upper $60 \mathrm{~cm}$ of the soil (Lott and Hammond, 2013). Second, the sale of vegetable produce is based on appearance and fresh weight (Sorensen, 2005). The sensitivity of vegetable crops to water stress may lead to dramatic fluctuations in yield, especially in droughtprone arid and semi-arid regions. In this context, additional drought-adaptive strategies in combination with DI can be used to sustain vegetable productivity and quality and to save water for future use in water-limited arid and semi-arid regions of the planet.

Soil amendment using biochar has been suggested as a strategy to improve long-term productivity and increase nutrient and water use efficiency (Sarong and Orge, 2015; Sohi et al., 2010). Biochar is a high-carbon coproduct of pyrolysis of organic matter that differs from charcoal by its intention of application as a soil amendment (Lehmann, 2007). The low density and large surface area of biochar provides the capacity for high adsorption, thus improving nutrient retention on the active surface and, consequently, reducing leaching and enhancing soil fertility (Nartey and Zhao, 2014). The porous structure of biochar can lower the bulk density of soil, thus increasing water retention. This ability to improve the water-holding capacity illustrates its application in regions where water deficit is a limiting factor for crop productivity (Briggs et al., 2005; Karhu et al., 2011). The potential soil factors altered 
by biochar addition, which may contribute to enhanced soil fertility and crop productivity, include soil physical properties (decreased bulk density, increased aeration, increased soil organic matter), chemical properties (increased nutrient availability, cation exchange capacity, decreased leaching), soil biological properties (provision of refuge and habitat, increased microbial activity due to high porosity and surface area), and plant properties, such as increased root growth and decreased disease incidence (Blanco-Canqui, 2017; Ding et al., 2016). Investing in such amendments can be especially beneficial for high-value vegetables because these crops generate much higher income per hectare for small farmers compared with staple crops (Abewoy, 2018). Several reports investigating the effects of biochar on growth, yield, physiology, and WUE of vegetable crops under deliberate water deficits are available in the literature. Ali et al. (2017) reviewed agricultural production (mainly agronomic crops) as affected by biochar amendments under drought and salt stress conditions. However, based on a survey of the literature, a comprehensive review abridging the role of biochar in vegetable production under deliberate water deficits is lacking. Therefore, we reviewed the potential of biochar as a soil amendment to alleviate yield losses and improve the growth and physiology of vegetable crops under DI, especially in waterlimited regions of the world.

\section{Impact of Deficit Irrigation Practices on Yield and Quality of Vegetable Crops}

The DI strategy involves deliberate exposure of crops to certain levels of water deficit, which conserves a significant amount of irrigation water and often causes some yield reductions depending on the ability of the plants to endure moisture stress. The physiological responses to DI and its effect on yield are crop- and cultivar-specific (Costa et al., 2007). Comprehensive knowledge of crop responses to small water deficiencies is vital for the successful practice of DI strategies. The effects of DI strategies on crop growth, physiology, WUE, and yield have been extensively investigated in vegetable crops. We surveyed the available literature for the application of DI for vegetable crops to determine its effect on the performance of various vegetables and the overall impact on vegetable production. In addition to the classical DI strategy, RDI and PRD are two frequently used DI strategies (Capra et al., 2008). With RDI, various phases of the crop cycle are subjected to water deficit to determine the phase that is least sensitive and has a minimum reduction in yield. However, PRD exposes the plant roots to alternate wetting and drying cycles, during which half of the root zone is exposed to water stress at one time. The existing literature indicated that the effects of these DI strategies on vegetable crop growth and yield are variable, ranging from significant yield reductions with minimal water deficits to statistically similar yields or even higher yields under DI in few cases (Table 1). Previously, a review of DI studies of horticultural crops by Costa et al. (2007) indicated that these strategies could be successfully practiced for several drought-tolerant fruit crops, but the outcomes are uncertain for stress-prone vegetable crops due to frequent losses in yield and quality. Capra et al. (2008) reviewed the feasibility of using DI strategies for different crops from the economic viewpoint of optimizing net returns. Recently, Sánchez-Blanco et al. (2019) performed a comprehensive review of the modifications in growth and adaption of ornamental plants in response to water deficits. The major responses of ornamental plants included decreased plant height, decreased leaf area, decreased shoot length, increased root length, increased root density, and increased root-to-shoot ratio. A comprehensive review of DI strategies used for vegetable crops is lacking because past reviews were based on a limited number of specific studies.

A total of 90 published articles comprising 134 reports were investigated to document the effects of DI strategies on the growth and yield of vegetable crops. The yield effects of various DI strategies on different vegetable crops are summarized in Table 1. Based on the reviewed reports, the yield results were considered decreased or nonsignificant (statistically similar), with few studies reporting increased yields under DI regimes. In most of these reports, yield results were compared at a $5 \%$ level of significance. If any of the DI levels produced statistically similar or higher yields than control irrigation (full irrigation), then it was recorded as nonsignificant or increased, respectively. Of these compiled studies, $\approx 52 \%$ of the reports showed a significant decrease in yield with all DI levels. Approximately $44 \%$ of reports with statistically similar yields under mild water deficits $\left(70 \%\right.$ to $\left.90 \% \mathrm{ET}_{\mathrm{c}}\right)$ were recorded, although higher levels of water deficits caused significant yield reductions. Among different vegetable crops, eggplant (Solanum melongena L.) and onion (Allium cepa L.) seem to perform well under water deficits, whereas leafy greens such as lettuce (Lactuca sativa L.) experienced consistent losses in yield

Table 1. Review of deficit irrigation (DI) studies of vegetable crops

\begin{tabular}{lcccc}
\hline & & \multicolumn{3}{c}{ Growth and yield reports (\%) } \\
\cline { 3 - 5 } Crop & $\begin{array}{c}\text { Number of } \\
\text { reports }\end{array}$ & Decreased & $\begin{array}{c}\text { No significant } \\
\text { difference }\end{array}$ & Increased \\
\hline Tomato & 33 & 42 & 52 & 6 \\
Pepper & 16 & 69 & 25 & 6 \\
Potato & 19 & 63 & 37 & 0 \\
Eggplant & 5 & 20 & 80 & 0 \\
Cucumber & 8 & 75 & 25 & 0 \\
Lettuce & 12 & 66 & 33 & 0 \\
Muskmelon & 10 & 50 & 30 & 0 \\
Watermelon & 13 & 62 & 38 & 0 \\
Squash & 2 & 50 & 50 & 0 \\
Onion & 7 & 14 & 86 & 0 \\
Sweet Corn & 4 & 25 & 75 & 0 \\
Green bean & 5 & 40 & 60 & 4 \\
Total & 134 & 52 & 44 & 0 \\
\hline
\end{tabular}

(Table 1). However, considering the differences among these studies with regard to the environment, cultivars, types of DI strategies, and DI levels, our ability to make strong conclusions using past literature is restricted. Because of these discrepancies, contrasting results have been reported, even within the same species. Lahoz et al. (2016) reported a $16.4 \%$ reduction in marketable tomato (Solanum lycopersicum L.) fruit yield with a mild water deficit $\left(75 \% \mathrm{ET}_{\mathrm{c}}\right)$ compared with full irrigation $\left(100 \% \mathrm{ET}_{\mathrm{c}}\right)$, whereas the total soluble solids (TSS) and lycopene content increased by $8.4 \%$ and $6.9 \%$, respectively. Nangare et al. (2016) concluded that fruit yields statistically similar to those with $100 \% \mathrm{ET}_{\mathrm{c}}$ could be obtained either with DI at $80 \% \mathrm{ET}_{\mathrm{c}}$ throughout the growing season or with $60 \% \mathrm{ET}_{\mathrm{c}}$ during the vegetative growth phase and $100 \%$ ETc during the remaining phases of the tomato crop. Recently, Hashem et al. (2018) observed 17.8\% and $15.2 \%$ declines in tomato fruit yields using RDI and PRD with a $30 \%$ water deficit $\left(70 \% \mathrm{ET}_{\mathrm{c}}\right)$, respectively. The yield losses were higher with RDI during the first year, whereas the lowest yield was obtained with PRD during the second year, which was in agreement with the transpiration rates. However, the ABA concentration in xylem was highest, and stomatal conductance $\left(g_{\mathrm{S}}\right)$ and photosynthesis were lowest with PRD during both years. The irrigation water use efficiency (IWUE) values were inconsistent because RDI treatment resulted in the lowest IWUE during the first year and the highest during the second year. Additionally, both water deficit treatments improved the TSS, titrable acidity, and vitamin $\mathrm{C}$ content of tomato fruits compared with full irrigation treatment. A potato (Solanum tuberosum L.) field study revealed that RDI and PRD treatments caused a substantial reduction in fresh as well as dry tuber yield compared with full irrigation treatment (Zin El-Abedin et al., 2017). The IWUE also declined under these DI treatments.

Ertek and Kara (2013) used four DI rates as a percentage of soil water deficit in sweet corn (Zea mays var. saccharata). It was suggested that $15 \%$ DI $(85 \%$ of full irrigation) could serve as an alternative to full irrigation without any significant decrease in 
the sweet corn yield. The protein and sugar contents, two important quality parameters for sweet corn, decreased at the highest level of irrigation and were found to be highest at $70 \%$ DI. Using a greenhouse experiment, Rahil and Qanadillo (2015) found that the cucumber (Cucumis sativus L.) crop yields under $70 \% \mathrm{ET}_{\mathrm{c}}$ irrigation treatment were $4 \%, 6 \%$, and $24 \%$ higher compared with $100 \% \mathrm{ET}_{\mathrm{c}}$, farmer irrigation, and tensiometer-based irrigation treatments, respectively. The water applied using farmer irrigation corresponded to the traditional application based on growth stage and plant observation. The tensiometer-based irrigation treatment involved the application of water when the reading approached 50-60 $\mathrm{kPa}$. The WUE was also found to be highest under $70 \% \mathrm{ET}_{\mathrm{c}}$, thereby saving a large amount of water.

To enhance the water extraction abilities under water stress, plants undergo root adjustments that may vary with the soil type and cultural amendments. This ability of the plants to modify root distribution can be a key mechanism to counter drought stress. Sharma et al. (2018) found that the root length intensity of reticulatus-type muskmelon increased in the deeper layers of soil under DI $\left(50 \% \mathrm{ET}_{\mathrm{c}}\right)$ compared with $100 \%$ $\mathrm{ET}_{\mathrm{c}}$. Similarly, the water shortage promoted root growth of sweet corn plants in deeper soil layers, displaying a significant increase in root dry matter with increasing water deficit for 2 consecutive years (Oktem, 2008). On the contrary, Wang et al. (2019) noted a decline in the total root volume, root surface area, and root weight density of a tomato crop with decreasing levels of irrigation. A greenhouse field study by Rahil and Qanadillo (2015) also revealed a decline in the underground biomass of cucumber plants when subjected to water deficit.

In most of the reviewed studies, small water deficits $\left(70 \%\right.$ to $\left.90 \% \mathrm{ET}_{\mathrm{c}}\right)$ increased the WUE of the majority of vegetable crops (Alenazi et al., 2015; Çolak et al., 2017; Kuşçu et al., 2015; Rop et al., 2016; Sezen et al., 2019), but often there was a loss in yields (Abd El-Mageed et al., 2017; Ierna and Mauromicale, 2018; Sezen et al., 2014). Nevertheless, a considerable number of reports revealed that similar yields or marginal declines in yields could be achieved using mild DI levels, thus saving significant amounts of irrigation water. The use of DI strategies for vegetable crops have the potential to improve water productivity, but the ability of vegetable crops to sustain crop productivity is uncertain because of frequent losses in yields, as revealed by past literature. To minimize yield losses in vegetable crops when using DI, Costa et al. (2007) suggested the integration of DI with other strategies such as protected cultivation or mulching. During recent years, biochar amendment has gained popularity as a drought management tool that is increasingly being investigated to determine its combination with DI strategies to sustain the productivity of different crops, including vegetables.

\section{How Might Biochar Improve Vegetable Productivity under Water Stress?}

Understanding the underlying mechanisms by which biochar amendments can improve crop yields, particularly by alleviating drought stress, is of considerable interest. Evaluating the capacity of biochar to increase soil water content and plant available water (PAW) is a key factor for determining its potential as a soil amendment for sustaining crop growth in water-limited regions. The water-holding capacity and PAW are largely determined as functions of the physical properties of soil. In recent years, the effects of biochar on the physical, chemical, and biological properties of soil have been extensively investigated and reviewed (Atkinson and Aitkenhead, 2018; Blanco-Canqui, 2017; Ding et al., 2016). Based on the published reports and literature reviews, biochar application generally increases soil porosity and decreases particle density and bulk density, although the degree of responses may vary with respect to soil type, biochar feedstock, pyrolysis conditions, and study duration (Spokas et al., 2012). For instance, these effects are more pronounced in sandy soils with coarse textures compared with clay soils with fine textures (Blanco-Canqui, 2017). The alteration in soil physical properties due to biochar addition is mainly attributed to its low density compared with soil particles. Furthermore, being a product of pyrolysis of organic material, biochar can serve as a binder and stimulate aggregate formation because of the strong correlation between organic matter content and aggregate stability (Blanco-Canqui, 2017; Jien and Wang, 2013; Verheijen et al., 2010). The literature review showed that biochar application has a positive influence on soil aggregate formation by increasing the wet aggregate stability significantly and improving the stability of dry aggregates to some extent; in turn, this improves the soil porosity and water movement. As indicated by the published literature, the addition of biochar causes an alteration in water infiltration and hydraulic conductivity depending on soil texture (Blanco-Canqui, 2017). Generally, water infiltration and hydraulic conductivity decrease with biochar addition in soils with coarse textures, increase in soils with fine textures, and remain nearly the same in soils with medium textures (Busscher et al., 2011; Githinji, 2013; Novak et al., 2016). However, these results are based mostly on short-term laboratory studies; therefore, further long-term field investigations to gain a better understanding of soil texture-biochar interactions are necessary.

The alterations in the water-holding capacity of soil have been widely studied (Paneque et al., 2016; Zhang et al., 2016). The application of biochar has shown a consistent increase in the water retention ability of soils, although the results are more noticeable in coarse-textured soils compared with fine-textured clay soils (Blanco-Canqui, 2017). By combining the available reports,
Blanco-Canqui (2017) found that the biochar addition increased the water-holding capacity of different soils in $90 \%$ of the studies. The increase in soil water content can improve PAW, which approximately occurs between field capacity and the permanent wilting point. However, an increase in water retention does not necessarily increase the PAW. Blanco-Canqui (2017) found that biochar had a positive effect on PAW in $72 \%$ of the reported cases.

Drought stress adversely affects the activity of soil microbes, which are known to have a crucial role in maintaining soil fertility, structure, soil respiration, and decomposition of soil organic matter (Tayyab, 2018). This is evident from the fact that $\approx 90 \%$ of the total soil organic matter is decomposed by soil microbes, which, in turn, determines the nutrient availability to the plants (Bastida et al., 2013). Among the soil microbial communities, the bacterial communities, which have a direct impact on soil structure and fertility, are highly affected by moisture stresses (York, 2012). Biochar benefits soil biota under drought stress by modifying the habitat, increasing available water, and stabilizing microbial activity during dry-wet cycles (Tayyab, 2018).

The improvements in water retention, PAW, and biological activity suggest that biochar incorporation may reduce the irrigation needs of vegetable crops and help save water in drought-prone regions without affecting crop productivity. Several studies combining the biochar amendment and reduced irrigation technique as an integrated approach with the aim of sustaining vegetable production in water-deficient areas were surveyed in literature, which will be further discussed in this review.

\section{Impact of Biochar on Growth, Yield, and Quality of Vegetables under DI}

Soil amendments using biochar have been reported to have positive effects on plant development, biomass production, and yield of many vegetable crops under moisture stress conditions. Mulcahy et al. (2013) observed an increase in the wilting resistance of tomato seedlings raised in pots with the application of $30 \%(\mathrm{v} / \mathrm{v})$ biochar prepared from wood pellets. Another greenhouse pot experiment performed by Akhtar et al. (2014) found that $5 \%(\mathrm{w} / \mathrm{w})$ application of rice (Oryza sativa L.) husk and cotton seed shell biochar increased the fruit yield of tomato plants subjected to $30 \%$ DI and partial rootzone drying irrigation by $6 \%$ and $13 \%$, respectively. In this study, the full irrigation treatment involved daily irrigation of pots to water-holding capacity. Biochar application also improved the fruit quality by increasing the titratable acidity, but its effects on TSS and vitamin $\mathrm{C}$ were not significant. A fairly similar trend was observed by Agbna et al. (2017), who reported an increase in titratable acidity, vitamin $\mathrm{C}$ content, and sugar/acid content ratios of tomato fruits with biochar addition without significantly affecting the 
TSS under all levels of irrigation. The plants exposed to water stress treatments had higher values for almost all of the quality parameters compared with the unstressed plants. During this greenhouse experiment, Agbna et al. (2017) found that the tomato plots that received $25 \mathrm{t} \cdot \mathrm{ha}^{-1}$ wheat straw biochar and water stress treatment had fruit yields that were statistically similar to those of the unstressed control plots. The increased yield was accompanied by increases in the plant height, number of leaves per plant, and fresh and dry plant weights. Li et al. (2018) drew similar conclusions from field experimentation; they reported that $30 \mathrm{t} \cdot \mathrm{ha}^{-1}$ biochar along with DI treatment can help save water without significantly affecting the total tomato productivity. In this experiment, increasing the application rates of maize straw biochar from 10 to $40 \mathrm{t} \cdot \mathrm{ha}^{-1}$ increased plant dry biomass and fruit yield, with higher application rates having nonsignificant effects or a negative impact on plant growth and yield. A cost-benefit analysis suggested that the net profit compared with that of nonbiochar treatment was positive with biochar applications of 10,20 , and $40 \mathrm{t} \cdot \mathrm{ha}^{-1}$ but negative with an application of $60 \mathrm{t} \cdot \mathrm{ha}^{-1}$. A quadratic function fitting net profit compared to the biochar application rate indicated that $27 \mathrm{t} \cdot \mathrm{ha}^{-1}$ was the optimal application rate. Recently, Langeroodi et al. (2019) observed maize straw biochar application of 10-15 $\mathrm{t} \cdot \mathrm{ha}^{-1}$ was a critical application rate for improving the seed yield for a pumpkin (Cucurbita pepo L.) crop subjected to water deficit stress.

After a 6-week greenhouse pot experiment, Batool et al. (2015) reported increases in leaf area, plant height, and dry weight of water-stressed okra (Abelmoschus esculentus L. Moench) plants with the addition of $1 \%$ (w/w) biochar prepared from stems of Lantana camara. Remarkably, the dry weight of stressed plants raised in biochar-amended pots was significantly higher compared with nonstressed untreated pots. Yakubu (2016) found that biochar improved the okra fruit yield under DI but had no significant effect under $\mathrm{ET}_{\mathrm{c}}$-based full irrigation, indicating that biochar effects are more prevalent in water-limited environments. A lysimeter experiment revealed that biochar application to sandy soil could enhance the growth, dry matter accumulation, and pod yield of green pea (Pisum sativum L.) plants under low water availability (Youssef et al., 2018). Pine wood biochar application $(2 \% \mathrm{w} / \mathrm{w})$, alone or its combination with compost and/or plant growth promoting rhizobacteria (PGPR), has been reported to be a promising strategy to enhance cucumber plant growth under drought stress (Nadeem et al., 2017). The addition of biochar to pots subjected to water deficit increased the root and shoot fresh weights and length of cucumber plants. However, the highest fresh weights and lengths were obtained when biochar, compost, and PGPR were applied in combination. Recently, Ali et al. (2018) observed that the application of biochar to cucumber field plots increased fresh and dry aboveground and underground biomass and the total yield of cucumber plants undergoing stress due to water deficit. In agreement with prior reports, biochar addition compensated for the loss in yields due to water deficit. On the contrary, Liu et al. (2017) reported a decrease in total plant biomass in biochar-treated potato pots under a reduced irrigation regime. This decline in biomass was correlated with reduced nitrogen $(\mathrm{N})$ and phosphorus $(\mathrm{P})$ uptake by plants, with the former having a greater impact. Additionally, biochar application also suppressed the activity of Arbuscular mycorrhizal fungi.

In general, the literature affirmed that biochar application could improve growth and minimize yield losses due to water deficits in vegetable crops, although the degree of response varied with crop species, soil type, and biochar material (Table 2). The addition of biochar also had beneficial effects on some quality parameters, but a limited number of reports are available. As expected, effective rates of biochar varied substantially among different soil types, and some of these inconsistencies in critical biochar rates may also be due to different crop species. One of the limitations of these biochar-DI studies was that most of these studies were conducted as greenhouse pot experiments. In potted soils, the natural structure of the soil is altered, thus disturbing soil biota and the balance between air and water, thereby modifying important soil physical properties such as bulk density, porosity, and water-holding capacity. Therefore, the pot experiments may not provide a true reflection of crop performance under natural field conditions.

\section{Impact of Biochar on Vegetable Physiology under DI}

Several physiological and morphological modifications occur in crop plants in response to drought stress. Loss of turgor due to moisture stress restricts cell elongation and division, leading to reduced plant growth (Lawlor and Cornic, 2002), which reduces the light interception. Water stress reduces the chlorophyll content and $g_{\mathrm{S}}$, subsequently moderating the photosynthetic activity. There is considerable evidence in the literature showing improvements in the physiology of water-stressed crop plants, including vegetables, with biochar application. The studies that explored the effects of biocharDI interactions on the physiology of vegetable crops are summarized in Table 2. Akhtar et al. (2014) reported that biochar addition significantly increased the photosynthetic rate $\left(P_{\mathrm{n}}\right)$ and relative water content (RWC) of tomato plants exposed to water deficiency, but that the chlorophyll content was higher in untreated plants. The reduction in the chlorophyll content of biochar-treated plants may be attributed to the adsorption of $\mathrm{NH}_{4}^{+}$ions on the biochar surface, resulting in reduced $\mathrm{N}$ uptake, which was evident from the lower leaf $\mathrm{N}$ content observed in biochar-treated plants compared with nonbiochar plants.
Similarly, Agbna et al. (2017) observed a significant improvement in $P_{\mathrm{n}}$ and leaf transpiration rates in stressed as well as nonstressed tomato plants treated with biochar. Biochar application ameliorated the declines in $g_{\mathrm{S}}$ and transpiration rates, and it significantly improved the $P_{\mathrm{n}}$ of okra plants exposed to drought stress over a period of 6 weeks (Batool et al., 2015). Water stress can induce physical and chemical modifications in biological membranes, subsequently affecting the membrane stability with respect to the leakage of ions such as sodium and potassium. Electrolyte leakage, measured as electrical conductivity due to effused ions from the leaves, is regarded as an indicator of membrane stability to moisture stress. Biochar application reduced electrolyte leakage from water-stressed as well as nonstressed cucumber plants (Nadeem et al., 2017). The chlorophyll content and RWC significantly decreased with increasing water deficits; however, biochar application displayed a compensatory effect by improving both these parameters (Nadeem et al., 2017). In a lysimeter experiment, Youssef et al. (2018) also reported an increase in chlorophyll content and RWC with biochar application for pea plants exposed to drought stress. Langeroodi et al. (2019) also reported a similar trend in a pumpkin field trial wherein $P_{\mathrm{n}}, g_{\mathrm{S}}$, chlorophyll content, transpiration rate, and RWC increased with increasing biochar rates from 0 to $20 \mathrm{t} \cdot \mathrm{ha}^{-1}$, although the increase was more evident in irrigation regimes with $75 \%$ and $90 \%$ of maximum allowable depletion of available soil water than irrigation treatments with $45 \%$ and $60 \%$ maximum allowable depletion, respectively.

\section{Impact of Biochar on WUE of Vegetable Crops under DI}

In water-limited arid and semi-arid regions, WUE serves as a good indicator of crop productivity as it relates to water use. Improvement in WUE implies decreased susceptibility of plants to water stress in drought-prone areas. The WUE could be increased by applying reduced irrigation and exposing the plants to small water deficits. However, drought-sensitive crops, especially vegetables, may show stress signs and losses in yield and quality. Biochar has been known to further increase the WUE of vegetables and alleviate drought stress symptoms. A summary of some reports used in this review is presented in Table 2. Akhtar et al. (2014) and Agbna et al. (2017) reported that biochar amendment improved the WUE of tomato plants exposed to water stress as well as nonstress treatments. A 2-year tomato field experiment revealed that water productivity (calculated as yield/actual ET) increased with biochar additions of $10,20,30$, and up to 40 t.ha ${ }^{-1}$ and decreased with higher application rates of $60 \mathrm{t} \cdot \mathrm{ha}^{-1}$ (Li et al., 2018). Similarly, biochar application increased the WUE of okra plants subjected to water deficit; the highest WUE was observed in biochartreated pots maintained at $60 \%$ field capacity. 


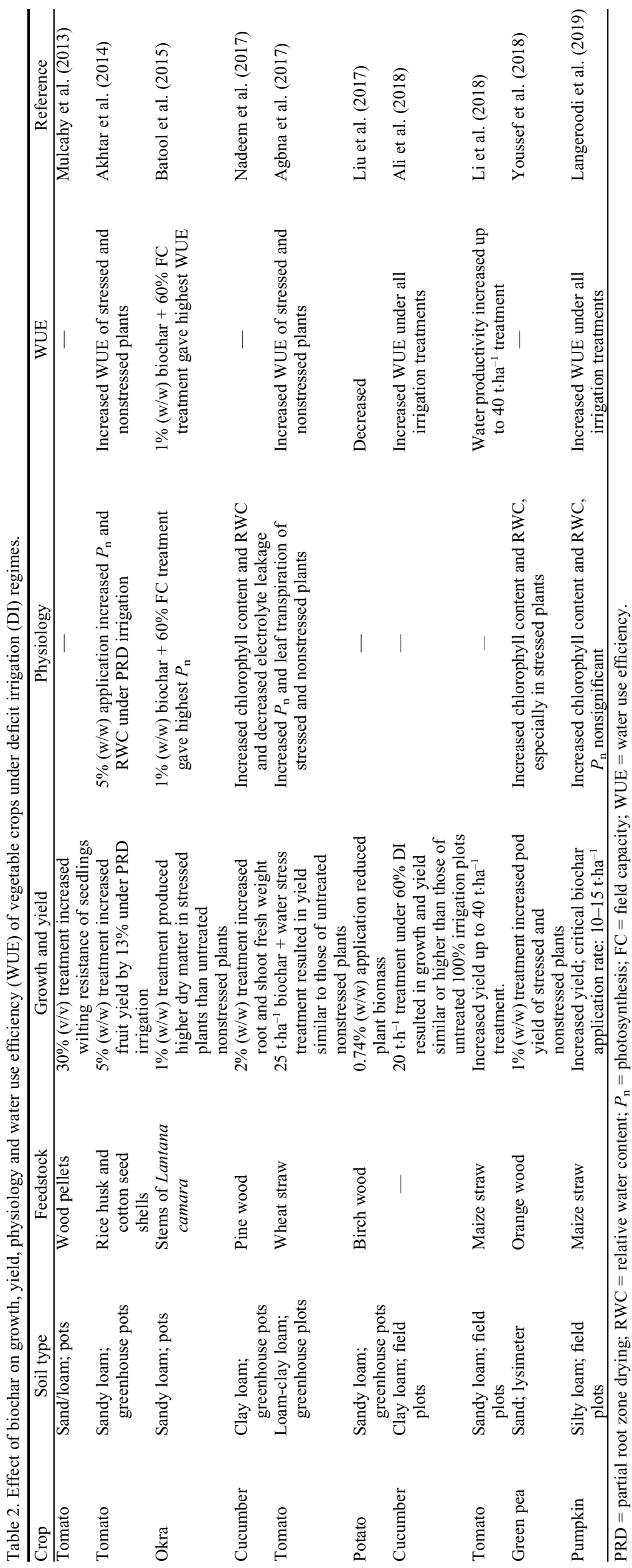

In a cucumber field experiment, WUE decreased significantly with decreasing irrigation levels; however, biochar application improved WUE under all levels of irrigation treatments (Ali et al., 2018). Recently, Langeroodi et al. (2019) observed a similar trend with biochar addition to pumpkin plots under different water stress levels. In contrast to these reports, Liu et al. (2017) witnessed a significant decrease in WUE with a corresponding decrease in plant biomass for biochar-treated potato pots compared with untreated pots under water stress. This decrease in WUE with biochar application was associated with decreased yield, which was attributed to reduced $\mathrm{N}$ and $\mathrm{P}$ uptake by the plants. Nevertheless, published reports indicated an overall increase in WUE with biochar addition, especially under moisture stress conditions.

\section{Conclusion}

Water scarcity is emerging as a major challenge for the agriculture sector, not only in water-limited arid and semi-arid areas but also in those regions that were originally water-sufficient. Agricultural sustainability demands serious adoption of water conservation strategies, especially in water-intensive vegetable production systems. The previous literature revealed that DI strategies improve the WUE of vegetable crops and could be used to save significant amounts of irrigation water. This has even greater relevance in waterscarce areas where water productivity is given more emphasis than production per unit area, with expected water use restrictions and higher water prices in the near future. However, an extensive review of DI for vegetable crops suggested that these practices are usually associated with yield losses, thereby causing uncertainty concerning the sustainability of vegetable productivity. Soil amendment using biochar is emerging as an effective water stress management practice. Improvement in the water retention capacity and PAW and the promotion of biological activity are the major mechanisms by which biochar benefits crop plant under moisture stress. Published reports have shown that biochar application under DI can compensate for the yield losses, improve crop physiology, and further increase the WUE of vegetable crops. In a broad sense, this review concluded that the combination of DI strategies and biochar amendments has the potential to serve as an effective approach to save water and sustain vegetable productivity. Nevertheless, there is ample opportunity and need to explore multiple soil/DI/biochar/plant interactions and close the research gaps by focusing on the following areas:

- Integration of DI and biochar has been studied in few vegetable species, and only a few reports exist. These interactions need to be investigated in more species. Simultaneous experimentation in different species will provide a perspective to compare the responses to these practices.

HortScience Vol. 54(11) November 2019 
- Most of these investigations have been performed in greenhouse or laboratory settings. With large variability in soil and climatic conditions, biochar effects under open field conditions may differ from controlled laboratory and greenhouse pot experiments. To extend practical recommendations, more open-field studies need to be conducted before large-scale deployment in the fields.

- Published results are largely based on short-term studies ( $\leq 2$ years). Biochar reactions and interactions with soil particles may vary over time, which would modify the physical and chemical properties of the soil. Long-term field studies could only verify the viability of these applications in the long-term. Collaboration with local farmers and starting with small acreage are some of the possibilities when initiating such long-term field experiments.

- The economic feasibility of DI and biochar amendments needs to be investigated and reviewed. In light of expected increments in water prices and restrictions in the near future, water productivity should also be taken into account. Biochar costs can be curtailed by testing and promoting the use of locally available organic material (e.g., crop residue) as feedstock.

- The crop simulation modeling approach could be followed to optimize DI levels and biochar rates for different vegetable crops under diverse soil and climate conditions.

\section{Literature Cited}

Abd El-Mageed, T.A., W.M. Semida, and M.M. Rady. 2017. Moringa leaf extract as biostimulant improves water use efficiency, physiobiochemical attributes of squash plants under deficit irrigation. Agr. Water Mgt. 193:46-54.

Abewoy, D., 2018. Review on impacts of climate change on vegetable production and its management practices. Advances in Crop Science and Technology 6:330.

Agbna, G.H.D., S. Dongli, L. Zhipeng, N.A. Elshaikh, S. Guangcheng, and L.C. Timm. 2017. Effects of deficit irrigation and biochar addition on the growth, yield, and quality of tomato. Scientia Hort. 222:90-101.

Ahmadi, S.H., M. Agharezaee, A.A. KamgarHaghighi, and A.R. Sepaskhah. 2014. Effects of dynamic and static deficit and partial root zone drying irrigation strategies on yield, tuber sizes distribution, and water productivity of two field grown potato cultivars. Agr. Water Mgt. 134:126-136.

Akhtar, S.S., G. Li, M.N. Andersen, and F. Liu. 2014. Biochar enhances yield and quality of tomato under reduced irrigation. Agr. Water Mgt. 138:37-44.

Alenazi, M., H. Abdel-Razzak, A. Ibrahim, M. Wahb-Allah, and A. Alsadon. 2015. Response of muskmelon cultivars to plastic mulch and irrigation regimes under greenhouse conditions. J. Anim. Plant Sci. 25:1398-1410.

Ali, A.B., Y. Haofang, L. Hong, W. Yan You, N.A. Elshaikh, G. Hussein, S. Pandab, and S. Hassan. 2018. Enhancement of depleted loam soil as well as cucumber productivity utilizing biochar under water stress. Commun. Soil Sci. Plant Anal. 50:49-64.

Ali, S., M. Rizwan, M.F. Qayyum, Y.S. Ok, M. Ibrahim, M. Riaz, M.S. Arif, F. Hafeez, M.I. Al-Wabel, and A.N. Shahzad. 2017. Biochar soil amendment on alleviation of drought and salt stress in plants: A critical review. Environ. Sci. Pollut. Res. Int. 24:12700-12712.

Atkinson, C.J. and M. Aitkenhead. 2018. How good is the evidence that soil-applied biochar improves water-holding capacity? Soil Use Mgt. 34:177-186.

Bastida, F., I.F. Torres, T. Hernández, P. Bombach, H.H. Richnow, and C. García. 2013. Can the labile carbon contribute to carbon immobilization in semiarid soils? Priming effects and microbial community dynamics. Soil Biol. Biochem. 57:892-902.

Batool, A., S. Taj, A. Rashid, A. Khalid, S. Qadeer, A.R. Saleem, and M.A. Ghufran. 2015. Potential of soil amendments (Biochar and Gypsum) in increasing water use efficiency of Abelmoschus esculentus L. Moench. Front. Plant Sci. $6: 733$.

Blanco-Canqui, H. 2017. Biochar and Soil Physical Properties. Soil Sci. Soc. Amer. J. 81:687-711.

Bodner, G., A. Nakhforoosh, and H.-P. Kaul. 2015. Management of crop water under drought: A review. Agron. Sustain. Dev. 35:401-442.

Briggs, C.M., J. Breiner, and R. Graham. 2005. Contributions of Pinus Ponderosa charcoal to soil chemical and physical properties. Proceedings of the ASA-CSSA-SSSA International Annual Meetings, Salt Lake City, UT.

Busscher, W.J., J.M. Novak, and M. Ahmedna. 2011. Physical effects of organic matter amendment of a southeastern US coastal loamy sand. Soil Sci. 176:661-667.

Capra, A., S. Consoli, and B. Scicolone. 2008. Deficit irrigation: Theory and practice, p. 5382. In: D. Alonso and H.J. Iglesias (eds.). Agricultural irrigation research progress. Nova Science Publishers, Hauppauge, NY.

Chai, Q., Y. Gan, C. Zhao, H.-L. Xu, R.M. Waskom, Y. Niu, and K.H.M. Siddique. 2015. Regulated deficit irrigation for crop production under drought stress. A review. Agron. Sustain. Dev. 36:3.

Çolak, Y.B., A. Yazar, S. Sesveren, and İ. Çolak. 2017. Evaluation of yield and leaf water potential (LWP) for eggplant under varying irrigation regimes using surface and subsurface drip systems. Scientia Hort. 219:10-21.

Costa, J.M., M.F. Ortuño, and M.M. Chaves. 2007. Deficit irrigation as a strategy to save water: Physiology and potential application to horticulture. J. Integr. Plant Biol. 49:1421-1434.

Ding, Y., Y. Liu, S. Liu, Z. Li, X. Tan, X. Huang, G. Zeng, L. Zhou, and B. Zheng. 2016. Biochar to improve soil fertility. A review. Agron. Sustain. Dev. 36:36.

Du, Y.-D., H.-X. Cao, S.-Q. Liu, X.-b. Gu, and Y.-X. Cao. 2017. Response of yield, quality, water and nitrogen use efficiency of tomato to different levels of water and nitrogen under drip irrigation in Northwestern China. J. Integr. Agr. 16:11531161.

Ertek, A. and B. Kara. 2013. Yield and quality of sweet corn under deficit irrigation. Agr. Water Mgt. 129:138-144.

FAO. 1993. Water resource issues and agriculture The State of Food and Agriculture, Rome, Italy. <http://www.fao.org/3/t0800e/t0800e0a. htm\#TopOfPage $>$.

FAO. 2002. Water Reports: Deficit irrigation practices. Rome, Italy. <http://www.fao.org/tempref/ agl/AGLW/ESPIM/CD-ROM/documents/5K_ e.pdf $>$.
Githinji, L. 2013. Effect of biochar application rate on soil physical and hydraulic properties of a sandy loam. Arch. Agron. Soil Sci. 60:457470 .

Hashem, M.S., T.Z. El-Abedin, and H.M. AlGhobari. 2018. Assessing effects of deficit irrigation techniques on water productivity of tomato for subsurface drip irrigation system. Int. J. Agr. Biol. Eng. 11:156-167.

Ierna, A. and G. Mauromicale. 2018. Potato growth, yield and water productivity response to different irrigation and fertilization regimes. Agr. Water Mgt. 201:21-26.

Jien, S.-H. and C.-S. Wang. 2013. Effects of biochar on soil properties and erosion potential in a highly weathered soil. Catena 110:225233.

Karhu, K., T. Mattila, I. Bergström, and K. Regina. 2011. Biochar addition to agricultural soil increased $\mathrm{CH} 4$ uptake and water holding capacity - Results from a short-term pilot field study. Agr. Ecosyst. Environ. 140:309-313.

Kirda, C. 2002. Deficit irrigation scheduling based on plant growth stages showing water stress tolerance. FAO, Food and Agriculture Organization of the United Nations (FAO).

Kirnak, H. and M.N. Demirtas. 2006. Effects of different irrigation regimes and mulches on yield and macronutrition levels of drip-irrigated cucumber under open field conditions. J. Plant Nutr. 29:1675-1690.

Kuşçu, H., A. Turhan, N. Özmen, P. Aydınol, H. Büyükcangaz, and A. Demir. 2015. Deficit irrigation effects on watermelon (Citrullus Vulgaris) in a sub humid environment. J. Anim. Plant Sci. 25:1652-1659.

Lahoz, I., A. Pérez-de-Castro, M. Valcárcel, J.I. Macua, J. Beltrán, S. Roselló, and J. CebollaCornejo. 2016. Effect of water deficit on the agronomical performance and quality of processing tomato. Scientia Hort. 200:55-65.

Langeroodi, A.R.S., E. Campiglia, R. Mancinelli, and E. Radicetti. 2019. Can biochar improve pumpkin productivity and its physiological characteristics under reduced irrigation regimes? Scientia Hort. 247:195-204.

Lawlor, D.W. and G. Cornic. 2002. Photosynthetic carbon assimilation and associated metabolism in relation to water deficits in higher plants. Plant Cell Environ. 25:275-294.

Lehmann, J. 2007. A handful of carbon. Nature 447:143.

Li, C., Y. Xiong, Z. Qu, X. Xu, Q. Huang, and G. Huang. 2018. Impact of biochar addition on soil properties and water-fertilizer productivity of tomato in semi-arid region of Inner Mongolia, China. Geoderma 331:100-108.

Liu, C., F. Liu, S. Ravnskov, G.H. Rubaek, Z. Sun, and M.N. Andersen. 2017. Impact of wood biochar and its interactions with mycorrhizal fungi, phosphorus fertilization and irrigation strategies on potato growth. J. Agron. Crop Sci. 203:131-145.

Lott, D.E. and V.E. Hammond. 2013. Water wise vegetable and fruit production. University of Nebraska-Lincoln Extension, Institute of Agriculture and Natural Resources, US. <http:// extensionpublications.unl.edu/assets/pdf/g2189. pdf>.

McGuire, V.L. 2017. Water-level and recoverable water in storage changes, High Plains aquifer, predevelopment to 2015 and 2013-15. US Geological Survey.

Mekonnen, M.M. and A.Y. Hoekstra. 2016. Four billion people facing severe water scarcity. Sci. Adv. 2:e1500323.

Mulcahy, D.N., D.L. Mulcahy, and D. Dietz. 2013. Biochar soil amendment increases tomato 
seedling resistance to drought in sandy soils. J. Arid Environ. 88:222-225.

Nadeem, S.M., M. Imran, M. Naveed, M.Y. Khan, M. Ahmad, Z.A. Zahir, and D.E. Crowley. 2017. Synergistic use of biochar, compost and plant growth-promoting rhizobacteria for enhancing cucumber growth under water deficit conditions. J. Sci. Food Agr. 97:5139-5145.

Nagaz, K., M.M. Masmoudi, and N. Ben Mechlia. 2012. Yield response of drip-irrigated onion under full and deficit irrigation with saline water in arid regions of Tunisia. ISRN Agronomy 2012:1-8.

Nangare, D.D., Y. Singh, P.S. Kumar, and P.S. Minhas. 2016. Growth, fruit yield and quality of tomato (Lycopersicon esculentum Mill.) as affected by deficit irrigation regulated on phenological basis. Agr. Water Mgt. 171:73-79.

Nartey, O.D. and B. Zhao. 2014. Biochar preparation, characterization, and adsorptive capacity and its effect on bioavailability of contaminants: An overview. Adv. Mater. Sci. Eng. 2014:1-12.

Novak, J., G. Sigua, D. Watts, K. Cantrell, P. Shumaker, A. Szogi, M.G. Johnson, and K. Spokas. 2016. Biochars impact on water infiltration and water quality through a compacted subsoil layer. Chemosphere 142:160-167.

Oktem, A. 2008. Effects of deficit irrigation on some yield characteristics of sweet corn. Bangladesh J. Bot. 37:127-131.

Paneque, M., J.M. De la Rosa, J.D. Franco-Navarro, J.M. Colmenero-Flores, and H. Knicker. 2016. Effect of biochar amendment on morphology, productivity and water relations of sunflower plants under non-irrigation conditions. Catena 147:280-287.

Rahil, M.H. and A. Qanadillo. 2015. Effects of different irrigation regimes on yield and water use efficiency of cucumber crop. Agr. Water Mgt. 148:10-15.

Rop, D.K., E.C. Kipkorir, and J.K. Taragon. 2016. Effects of deficit irrigation on yield and quality of onion crop. J. Agr. Sci. 8:112-124.
Sánchez-Blanco, M.J., M.F. Ortuño, S. Bañon, and S. Álvarez. 2019. Deficit irrigation as a strategy to control growth in ornamental plants and enhance their ability to adapt to drought conditions. J. Hort. Sci. Biotechnol. 94:137-150.

Sarong, M. and R.F. Orge. 2015. Effect of rice hull biochar on the fertility and nutrient holding capacity of sandy soils. OIDA International Journal of Sustainable Development 8:33-44.

Sezen, S.M., A. Yazar, Y. Daşgan, S. Yucel, A. Akyıldız, S. Tekin, and Y. Akhoundnejad. 2014. Evaluation of crop water stress index (CWSI) for red pepper with drip and furrow irrigation under varying irrigation regimes. Agr. Water Mgt. 143:59-70.

Sezen, S.M., A. Yazar, and S. Tekin. 2019. Physiological response of red pepper to different irrigation regimes under drip irrigation in the Mediterranean region of Turkey. Scientia Hort. 245:280-288.

Sharma, S.P., D.I. Leskovar, A. Volder, K.M. Crosby, and A.M.H. Ibrahim. 2018. Root distribution patterns of reticulatus and inodorus melon (Cucumis melo L.) under subsurface deficit irrigation. Irr. Sci. 36:301-317.

Singh, S., S.V. Angadi, K. Grover, S. Begna, and D. Auld. 2016. Drought response and yield formation of spring safflower under different water regimes in the semiarid Southern High Plains. Agr. Water Mgt. 163:354-362.

Sohi, S.P., E. Krull, E. Lopez-Capel, and R. Bol. 2010. A review of biochar and its use and function in soil, p. 47-82. Advances in agronomy. Academic Press, Cambridge, MA.

Sorensen, E.J. 2005. WSU drought advisory: Vegetable crops. Washington State University, Pullman, US. $<$ https://research.libraries.wsu.edu: 8443/xmlui/bitstream/handle/2376/7035/em4830. pdf? sequence $=1 \&$ isAllowed $=\mathrm{y}>$.

Spokas, K.A., K.B. Cantrell, J.M. Novak, D.W. Archer, J.A. Ippolito, H.P. Collins, A.A. Boateng, I.M. Lima, M.C. Lamb, A.J. McAloon, R.D. Lentz, and K.A. Nichols. 2012. Biochar: A synthesis of its agronomic impact beyond carbon sequestration. J. Environ. Qual. 41:973-989.

Tayyab, M. 2018. Biochar: An efficient way to manage low water availability in plants. Appl. Ecol. Environ. Res. 16:2565-2583.

Verheijen, F., S. Jeffery, A. Bastos, M. Velde, and I. Diafas. 2010. Biochar application to soils - A critical scientific review of effects on soil properties, processes and functions. European Commission Publication Office, Luxembourg.

Wang, X., J. Yun, P. Shi, Z. Li, P. Li, and Y. Xing. 2019. Root growth, fruit yield and water use efficiency of greenhouse grown tomato under different irrigation regimes and nitrogen levels. J. Plant Growth Regul. 38:400-415.

Yakubu, A. 2016. Estimating crop water requirement and yield of okra in biochar amended soil. University of Ghana, Ghana.

Yang, C., Y. Luo, L. Sun, and N. Wu. 2015. Effect of deficit irrigation on the growth, water use characteristics and yield of cotton in arid northwest China. Pedosphere 25:910-924.

York, A. 2012. Aboveground-belowground linkages. Biotic interactions, ecosystem processes, and global change. In: R.D. Bardgett and D.A. Wardle (eds.). Oxford University Press, Oxford, 2010. Austral Ecol. 37:e26-e27.

Youssef, S., G. Riad, N. Abu El-Azm, and E. Ahmed. 2018. Amending sandy soil with biochar or/and superabsorbent polymer mitigates the adverse effects of drought stress on green pea. Egypt. J. Hort. 45:169-183.

Zhang, J., Q. Chen, and C. You. 2016. Biochar effect on water evaporation and hydraulic conductivity in sandy soil. Pedosphere 26:265-272.

Zin El-Abedin, T.K., M.A. Mattar, A.A. Alazba, and H.M. Al-Ghobari. 2017. Comparative effects of two water-saving irrigation techniques on soil water status, yield, and water use efficiency in potato. Scientia Hort. 225:525-532. 